\title{
FRACTURE MECHANICS CRITICAL ASSESSEMENT OF THE STEEL STRUCTURES JOINTS
}

\author{
Dorin Radu ${ }^{1}$ \\ Teofil Galațanu ${ }^{2}$
}

UDK: 539.42:624.014.2

DOI:10.14415/konferencijaGFS2017.026

Summary: Elaboration of a methodology for determining the acceptability of detected cracks/flaws in a structure, has a major practical importance in the overall assessment and life integrity of a structure. The relation given by fracture mechanics links a parameter which describes the stress intensity at a crack tip to a material characteristic-fracture toughness. This relation provides the possibility of assessing the fracture conditions of the structural elements with defects (cracks) [1].

The present paper is proposing assessing the structural elements welded joints from the fracture mechanics point of view. The analysis is carried out in accordance with the British Standard procedure BS 7910 ('Guide to methods for assessing the acceptability of flaws in metallic structures')[5]

Keywords: Fracture mechanics, steel structures, structural integrity

\section{INTRODUCTION}

Most welding fabrication codes specify maximum tolerable flaw sizes and minimum tolerable Charpy energy, based on good workmanship, i.e. what can reasonably be expected within normal working practices. These requirements tend to be somewhat arbitrary, and failure to achieve them does not necessarily mean that the structure is at risk of failure. An Engineering Critical Assessment (ECA) is an analysis, based on fracture mechanics principles, of whether or not a given flaw is safe from brittle fracture, fatigue, creep or plastic collapse under specified loading conditions. An ECA can be used: during design, to assist in the choice of welding procedure and/or inspection techniques; during fabrication, to assess the significance of: a) known defects which are unacceptable to a given code [2], or b) a failure to meet the toughness requirements of a fabrication code; during operation, to assess flaws found in service and to make decisions as to whether they can safely remain, or whether down-rating/repair are necessary. This type of assessing can be done if the following elements are known: material fracture toughness, geometry and size of the crack, resulted stresses from the applied forces.

The fracture mechanics based methodologies are permitting the following types of assessments:

\footnotetext{
${ }^{1}$ Assist. Eng. Dorin Radu, Phd., Transilvania University of Brașov, Faculty of Civil Engineering, Turnului 5, Brașov, Romania, tel: +40 268548 228, e - mail: dorin.radu@unitbv.ro

${ }^{2}$ Lect. Eng. Teofil Florin Galatanu, PhD, Transilvania University of Braşov, Faculty of Civil Engineering, Turnului 5, Braşov, Romania, tel: +40 268548 228, e - mail: galatanu.teofil@ unitbv.ro
} 
- Maximal crack dimension assessment to which the structural element will not fail, named also the admissible crack dimension; for this type of assessing is needed the maximal stresses values and the value of the material fracture toughness;

- Maximal stress value assessment to which the structural element with a crack will not fail

- Minimal fracture toughness value assessment to the structural element with a crack; this assessment needs knowing the maximal stress value and the admissible crack dimensions. Considering a simple case - a steel plate under tension (figure 1), can be underlined the following types of fracture: Brittle fracture - controlled by the value of the applied tension force, dimension of the crack, material fracture toughness and geometry of the element; Plastic fracture - the net section in which the yielding phenomena appears, controlled by the applied tension force value, the yielding limit and the element geometry; Rupture as a result of extended material yielding, controlled by the applied tension force, crack size, material fracture toughness and the element geometry.

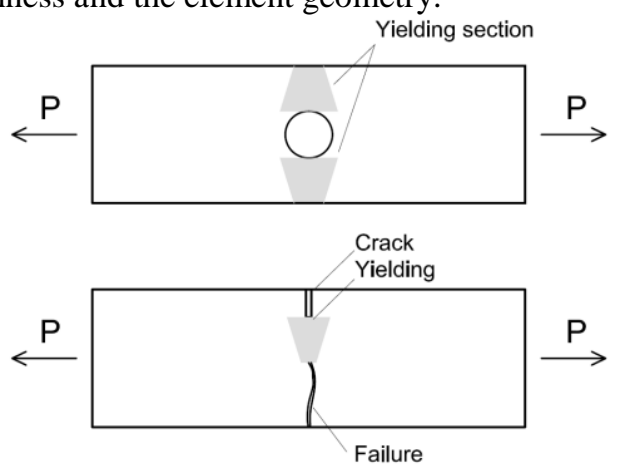

Figure 1. Describing fracture - plate under tension

The transition domain between these types of fracture is governed by the interaction between the brittle fracture and the plastic failure. This is expressed through a dependency relation of two parameters $K_{r}$ and $S_{r}$. These parameters are defined based on the geometrical dimensions of the structural element, crack dimensions and geometry, stresses that appear in the cross section following the applied loads, taken into account the fracture toughness of the material $K_{\text {mat }}$.

\section{FAILURE ASSESSEMENT DIAGRAMS - FAD 2}

The Failure Assessment Diagram (FAD) describes the interaction between the brittle fracture and plastic failure through a $F_{f}=f\left(S_{r}\right)$ function.

Structures using reasonably tough materials (high $K_{I c}$ ) and having only small cracks (low $K$ ) will lie in the strength-of-materials regime. Conversely, if the material is brittle (low $K_{I c}$ ) and strong $S_{r}$ (high yield strength), the presence of even a small crack is likely to trigger fracture. Thus, the fracture mechanics assessment is a crucial one. The special circumstances that would be called into play in the upper right corner of figure 2 in this regime, a cracked structure would experience large-scale plastic deformation prior to crack extension. 
Contemporary achievements in civil engineering 21. April 2017. Subotica, SERBIA

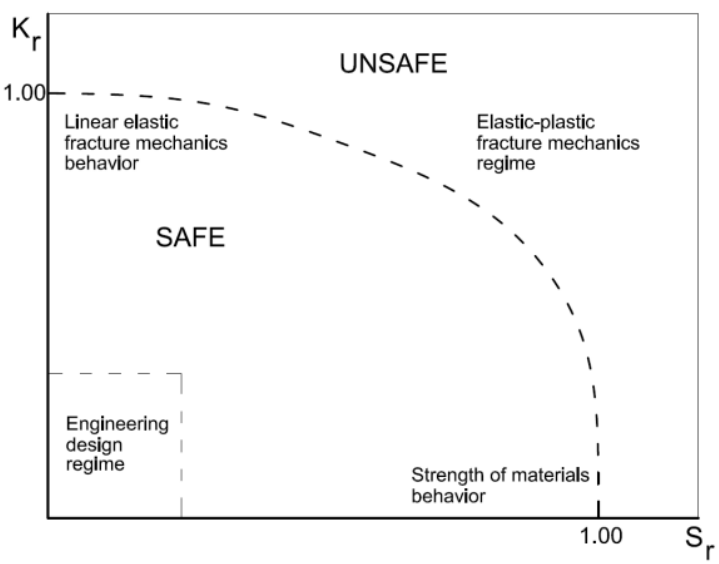

Figure 2. General plot of the ratios of the toughness and stress showing the relationship between linear elastic fracture mechanics and strength of materials as it relates to fracture and structural integrity [3]

The level 2 (FAD-2) assessment is the normal evaluation path for general application. The method is presenting an assessment line given by an equation of a curve and a cut-off line. If the assessment point is in the interior of the surface limited by the assessment line, the flaw is acceptable and if the assessment point is at the outside area, the flaw is considered unacceptable.

The equations which are describing the assessment line are:

$$
\begin{gathered}
\sqrt{\delta_{r}} \text { or } K_{r}=\left(1-0,14 L_{r}^{2}\right)\left[0,30+0,70 \exp \left(-0.65 L_{r}^{6}\right)\right] \text { for } L_{r} \leq L_{r \max } \\
\sqrt{\delta_{r}} \text { or } K_{r}=0 \text { for } L_{r}>L_{r \max }
\end{gathered}
$$

The cut-of line is fixed in point where $L_{r}=L_{r \max }$ where:

$$
L_{r \max }=\left(\sigma_{Y}+\sigma_{u}\right) /\left(2 \sigma_{Y}\right)
$$

in which:

$\sigma_{Y}-$ the yielding resistance of the material

$\sigma_{u}$ - the ultimate resistance of the material

For the assessment on level 2 FAD is necessary to pass through the following phases [4]:

- Determining the stresses - following a structural analysis. The assessments are considering the real distribution of the stresses in the proximity of the flaws $-P_{m}$, $P_{b}, Q_{m}$ and $Q_{b}$.

- The fracture ratio $K_{r}$ must be determined

$$
K_{r}=K_{I} / K_{m a t}
$$

in which $K_{\text {mat }}$ represents the fracture toughness of the assessed material, determined at the service temperature. relation:

The stress intensity factor (SIF) $-K_{I}$ is determined with the following

where

$$
K_{I}=(Y \cdot \sigma) \cdot(\pi \cdot a)^{1 / 2}
$$

$$
Y \cdot \sigma=(Y \cdot \sigma)_{P}+(Y \cdot \sigma)_{S}
$$


in which:

$$
\begin{gathered}
(Y \cdot \sigma)_{P} \quad-\text { contribution of the main stresses } \\
(Y \cdot \sigma)_{S} \quad-\text { contribution of the secondary stresses } \\
(Y \cdot \sigma)_{P}=M \cdot f_{w} \cdot\left\{k_{t m} \cdot M_{k m} \cdot M_{m} \cdot P_{m}+k_{t b} \cdot M_{k b} \cdot M_{b} \cdot\left[P_{b}+\left(k_{m}-1\right) P_{m}\right]\right\} \\
(Y \cdot \sigma)_{S}=M_{m} \cdot Q_{m}+M_{b} \cdot Q_{b}
\end{gathered}
$$

- Determining the ratio of stress $L_{r}$ according with:

$$
L_{r}=\sigma_{r e f} / \sigma_{Y}
$$

in which $\sigma_{\text {ref }}$ is obtain according with a relation specific with the flaw type. The point/points of assessment are represented graphically in $\left(K_{r}, L_{r}\right)$ coordinates on the FAD level 2 [5].

- The evaluation of the position of the point is done according with the specifications done.

As a study case, there is presented an existing structure - wind turbine column. Following visual inspection and NDT testing, there were discovered several flaws - cracklike type. An indepth study was needed in order to conclude upon the realibility and safety of the structure.

In case of assessment level $2-\mathrm{FAD}-2$, there were done assessments on different flaws type and flaws positon for the in case. The values of the input data are:

- $\sigma_{Y}$ (yield strength) $=355 \mathrm{MPa} ; \sigma_{T}$ (ultimate strength)= $510 \mathrm{MPa}$; S355J2 steel type

- $K_{\text {mat }}=81,8 \mathrm{MPa} \cdot \mathrm{m}^{1 / 2}$ was determined on the specimens (through testing)

- $P_{m}=251 \mathrm{MPa}$ - Primary stress - determined following a structural analysis

\begin{tabular}{|c|c|c|c|}
\hline Case no. & Name & Flaw type & Description of the flaw \\
\hline Case 1 & (TTF-1) & through thickness flaw & $\begin{array}{l}\text { Crack in the tube wall in the proximity of the welded } \\
\text { joint }\end{array}$ \\
\hline Case 2 & (TTF-2) & through thickness flaw & Crack in the welding longitudinal direction \\
\hline Case 3 & $(\mathrm{TTF}-3)$ & through thickness flaw & Crack in the welding transversal direction \\
\hline Case 4 & (TTF-4) & through thickness flaw & $\begin{array}{l}\text { Crack in the flange of the segment joint in proximity } \\
\text { of the welding longitudinal direction }\end{array}$ \\
\hline Case 5 & (TTF-5) & through thickness flaw & $\begin{array}{l}\text { Crack in the flange of the segment joint in proximity } \\
\text { of the welding transversal direction }\end{array}$ \\
\hline Case 6 & $(\mathrm{EF}-1)$ & edge flaw & $\begin{array}{l}\text { Crack in the tube wall in the proximity of the welded } \\
\text { joint }\end{array}$ \\
\hline Case 7 & $(\mathrm{EF}-2)$ & edge flaw & Crack in the welding longitudinal direction \\
\hline Case 8 & $(\mathrm{EF}-3)$ & edge flaw & Crack in the welding transversal direction \\
\hline Case 9 & $(\mathrm{EF}-4)$ & edge flaw & $\begin{array}{l}\text { Crack in the flange of the segment joint in proximity } \\
\text { of the welding longitudinal direction }\end{array}$ \\
\hline Case 10 & $(\mathrm{EF}-5)$ & edge flaw & $\begin{array}{l}\text { Crack in the flange of the segment joint in proximity } \\
\text { of the welding transversal direction }\end{array}$ \\
\hline
\end{tabular}

- $k_{t m}=1 ; k_{t b}=1$ (stress concentrators factors)

- $Q_{t m}=0$ (thermal membrane stress) and $Q_{t b}=0$ (thermal bending stress)

- $Q_{m}=0$ (residual membrane stress) and $Q_{b}=0$ (residual bending stress)

Table 1 - Flaw cases description 


\section{$5^{\text {th }}$ international CONFERENCE}

\section{Contemporary achievements in civil engineering 21. April 2017. Subotica, SERBIA}

Considering the position of the flaw regarding the stress direction and position in the assembly of the steel shell element, it resulted 10 types of assessed flaws as presented in table 1.

The flaws were considered as present in the steel shell elements. In a conservative manner, the $\mathrm{W}$ dimension at some part of the flaws types was considered $200 \mathrm{~mm}$, taken into account that the area of tension from the segment joint of the steel pillar, is about $200 \mathrm{~mm}$. Increasing the $\mathrm{W}$ dimension will decrease the safety of the structure in the area of the joint.

Table 2 - FAD 2 - in case - flaws assed: geometry and results (with corresponding figures and flaw name - figure 3 and 4)

\begin{tabular}{|c|c|c|c|c|c|c|c|c|c|c|c|c|}
\hline Fig. & Case & B & $\mathbf{W}$ & $2 a$ & $\mathbf{a}$ & $2 c$ & p & $\mathbf{r}_{0}$ & h & $t_{w}$ & $\mathbf{L}_{\mathrm{r}}$ & $\overline{\mathbf{K}_{\mathbf{r}}}$ \\
\hline \multirow[t]{2}{*}{ no. } & & $\mathrm{mm}$ & $\mathrm{mm}$ & $\mathrm{m}$ & $\mathrm{m}$ & $\mathrm{m}$ & $\mathrm{m}$ & $\mathrm{m}$ & $\mathrm{m}$ & $\mathrm{m}$ & & \\
\hline & & & & $\mathrm{m}$ & $\mathrm{m}$ & $\mathrm{m}$ & $\mathrm{m}$ & $\mathrm{m}$ & $\mathrm{m}$ & $\mathrm{m}$ & & \\
\hline \multirow[t]{10}{*}{3} & FP-TTF- & 16 & 200 & 30 & & & & & & & 0.831 & 0.675 \\
\hline & 1 & & & & & & & & & & 8 & 5 \\
\hline & FP-TTF- & 32.6 & 200 & 30 & & & & & & & 0.831 & 0.675 \\
\hline & 2 & 3 & & & & & & & & & 8 & 5 \\
\hline & FP-TTF- & 200 & 32.6 & 10 & & & & & & & 1.019 & 0.408 \\
\hline & 3 & & 3 & & & & & & & & 5 & 5 \\
\hline & FP-TTF- & 25 & 200 & 30 & & & & & & & 0.831 & 0.675 \\
\hline & 4 & & & & & & & & & & 8 & 5 \\
\hline & FP-TTF- & 25 & 120 & 30 & & & & & & & 0.942 & 0.693 \\
\hline & 5 & & & & & & & & & & 7 & 0 \\
\hline \multirow[t]{5}{*}{4} & FP-EF-1 & 16 & 200 & & 15 & & & & & & 0.7644 & 0.7688 \\
\hline & FP-EF-2 & 32.63 & 200 & & 15 & & & & & & 0.7644 & 0.7688 \\
\hline & FP-EF-3 & 200 & 32.63 & & 15 & & & & & & 1.3086 & 1.6678 \\
\hline & FP-EF-4 & 25 & 200 & & 15 & & & & & & 0.7644 & 0.7688 \\
\hline & FP-EF-5 & 25 & 120 & & 15 & & & & & & 0.8080 & 0.8139 \\
\hline
\end{tabular}

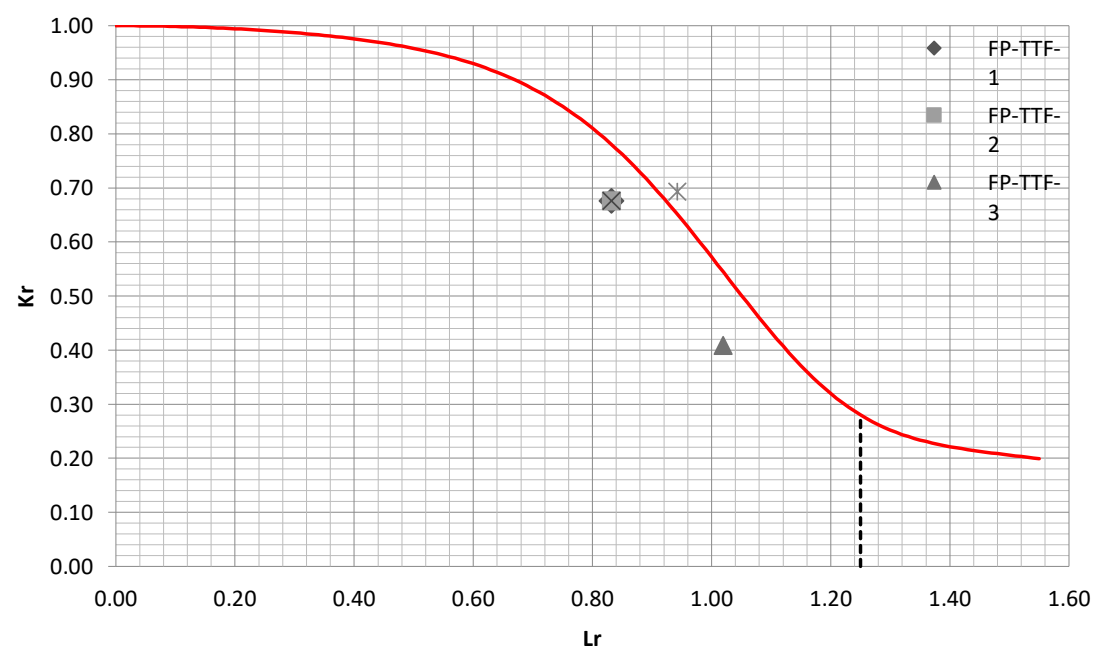

Figure 3. FP-TTF - Group of flaws - assessment 


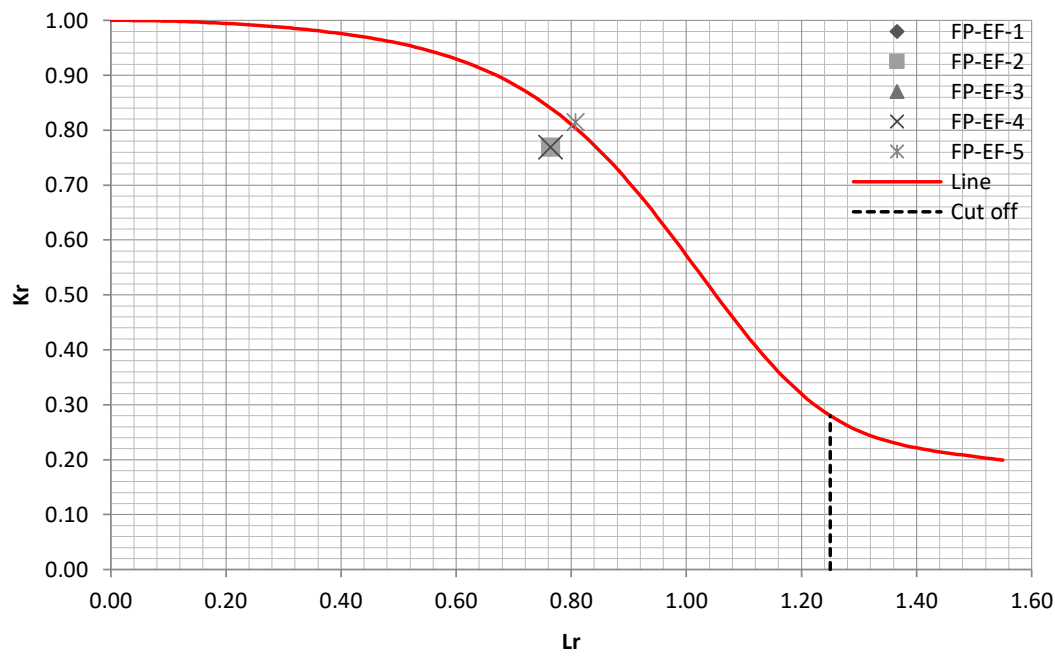

Figure 4. FP-EF-Group of flaws - assessment

With the presented procedure, further assessment can be made on the joint and steel shell element taken into account different dimensions. Figure 4 and 5 shows the assessment of the flaws grouped. It can be seen that the FP-TTF 5 - through thickness flaw - crack of $30 \mathrm{~mm}$ in the flange of the segment joint is a critical flaw - the assessment point is in the unsafe area of the diagram. Also the FP EF 5 - edge flaw in the flange of the segment joint is a critical flaw $-\mathrm{t} 15 \mathrm{~mm}$ flaw is putting under risk the joint and the structure.

\section{DETERMINING THE CRITICAL VALUE OF THE FLAW}

Determining the critical value of the flaws is important because it serves to a limit value for fatigue further analysis based on fracture mechanics principles, needed for

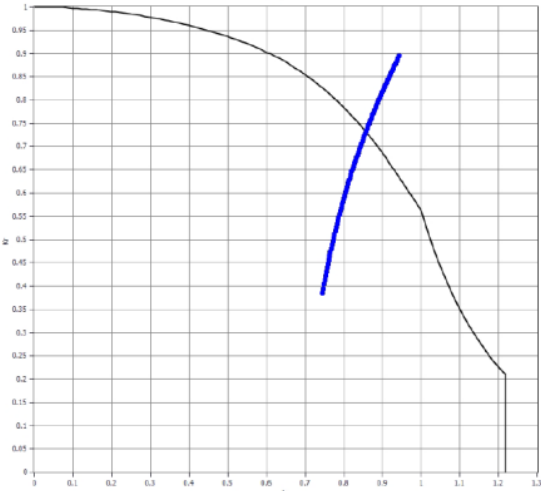

Figure 5. FP-TTF-1 critical flaw

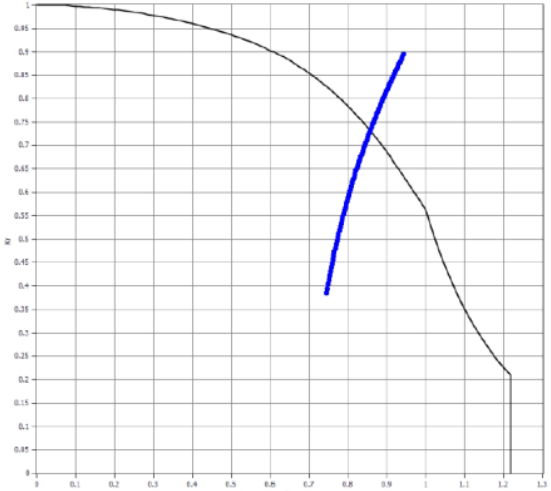

Figure 6. FP-TTF-2 critical flaw 
$5^{\text {th }}$ inTERnATIONAL CONFERENCE

Contemporary achievements in civil engineering 21. April 2017. Subotica, SERBIA

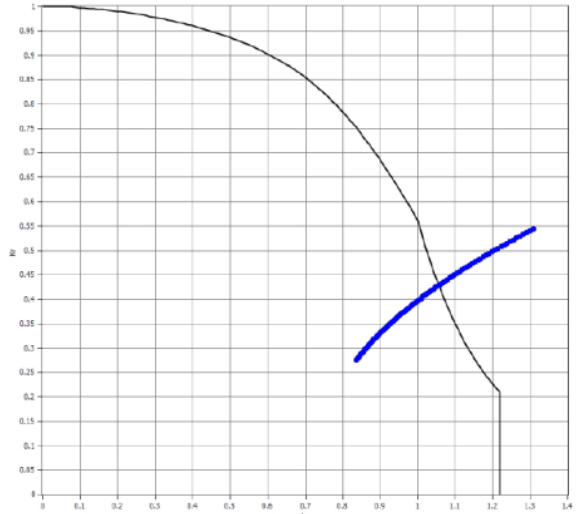

Figure 7. FP-TTF-3 critical flaw

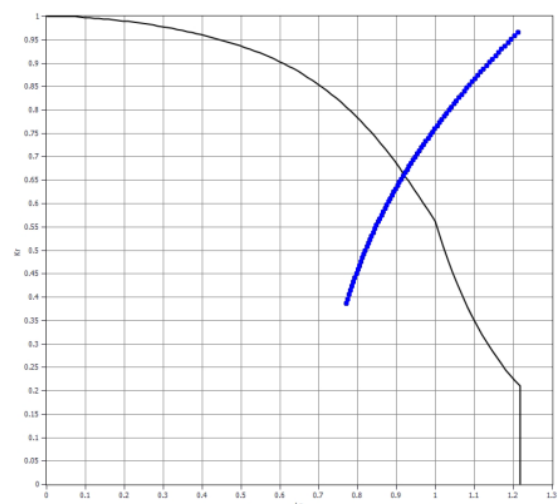

Figure 9. FP-TTF-5 critical flaw

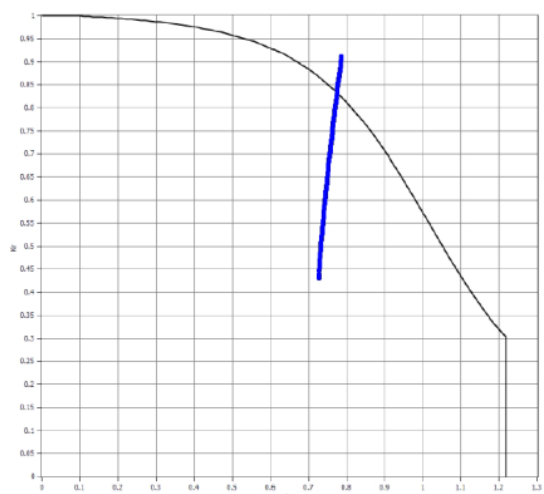

Figure 11. FP-EF-2 critical flaw

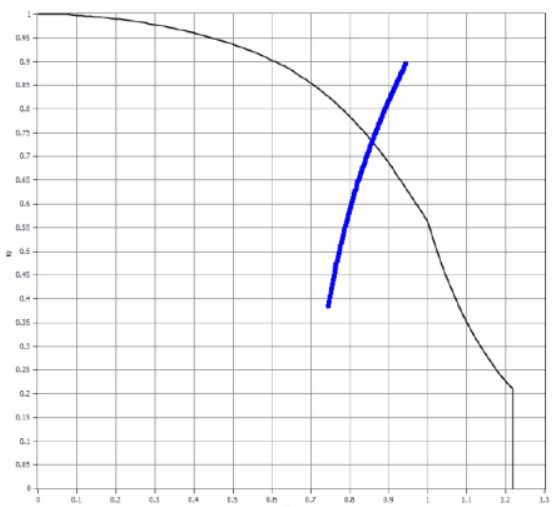

Figure 8. FP-TTF-4 critical flaw

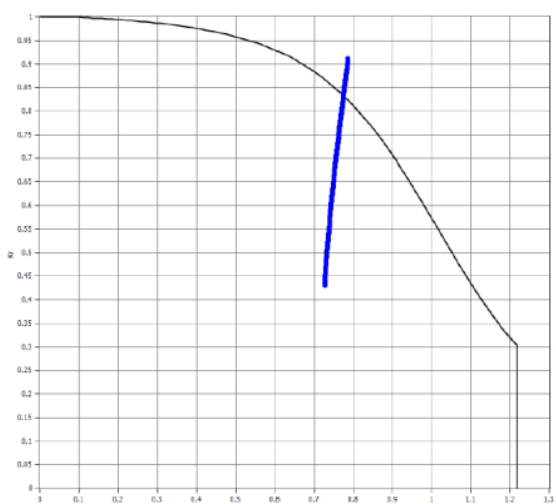

Figure 10. FP-EF-1 critical flaw

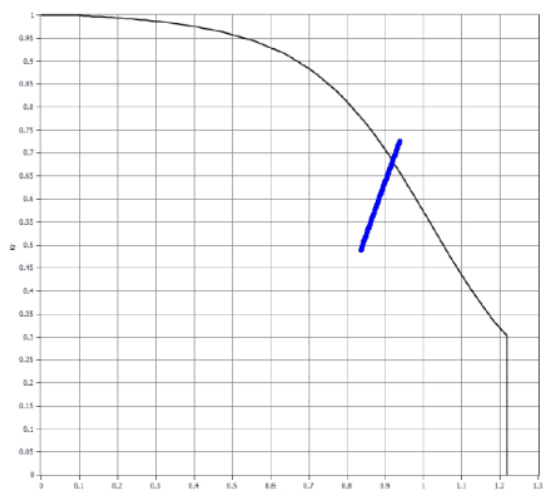

Figure 12. FP-EF-3 critical flaw 


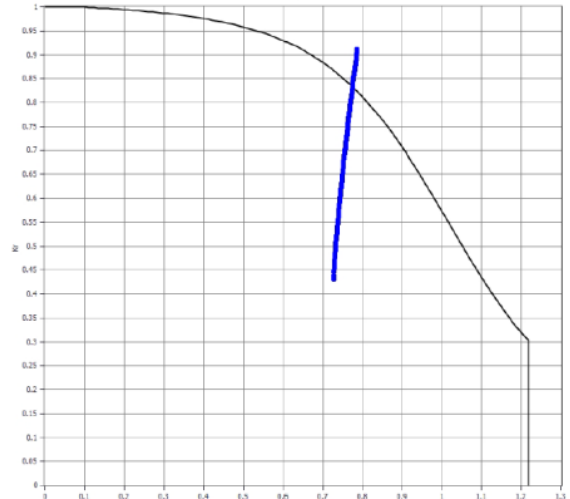

Figure 13. FP-EF-4 critical flaw

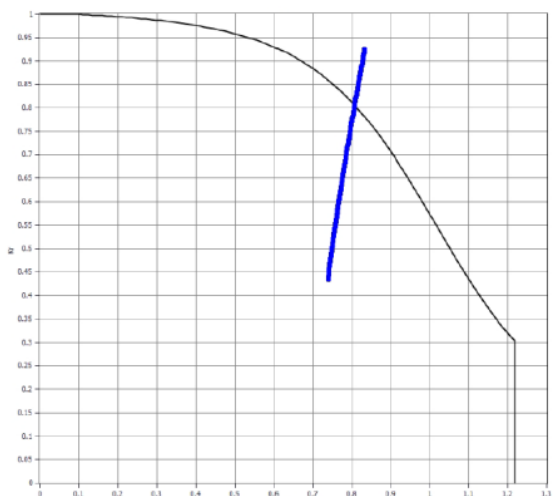

Figure 14. FP-EF-5 critical flaw

determining the number of cycles for a crack to extend from an initial dimension to a critical dimension which means the failure of the element.

The procedure uses FAD-2 assessment data, and it gives the critical dimension of the crack.

The input data is the same as for FAD-2 assessment. The results are presented in table 3 . The critical dimension of the crack for each case are represented in figures 5 to 14 .

Table 3. - FAD 2 - critical dimension of the flaw (with corresponding figures and flaw name)

\begin{tabular}{|c|c|c|c|c|c|c|c|c|c|c|c|c|}
\hline $\begin{array}{c}\text { Cas } \\
\text { eno } \\
\text {. }\end{array}$ & $\begin{array}{l}\text { Case } \\
\text { name }\end{array}$ & B & $\mathbf{W}$ & $2 a_{0}$ & $\mathbf{a}_{0}$ & $\begin{array}{c}2 c \\
0\end{array}$ & $\mathbf{p}_{0}$ & $\mathbf{r}_{0}$ & $\mathbf{h}_{0}$ & $\begin{array}{l}\mathbf{t} \\
\mathrm{w}\end{array}$ & $\begin{array}{c}\text { Flaw } \\
\text { Height } \\
\text { Critic } \\
\end{array}$ & $\begin{array}{c}\text { Flaw } \\
\text { Length } \\
\text { Critic }\end{array}$ \\
\hline & & $\mathrm{mm}$ & $\mathrm{mm}$ & $\begin{array}{l}\mathrm{m} \\
\mathrm{m}\end{array}$ & $\begin{array}{l}\mathrm{m} \\
\mathrm{m}\end{array}$ & $\begin{array}{l}\mathrm{m} \\
\mathrm{m}\end{array}$ & $\begin{array}{l}\mathrm{m} \\
\mathrm{m}\end{array}$ & $\begin{array}{l}\mathrm{m} \\
\mathrm{m}\end{array}$ & $\mathrm{mm}$ & $\begin{array}{l}\mathrm{m} \\
\mathrm{m}\end{array}$ & $\mathrm{mm}$ & $\mathrm{mm}$ \\
\hline 1 & $\begin{array}{l}\text { FP-TTF- } \\
1\end{array}$ & 16 & 200 & 30 & & & & & & & N/A & 36.249 \\
\hline 2 & $\begin{array}{l}\text { FP-TTF- } \\
2\end{array}$ & $\begin{array}{r}32.6 \\
3\end{array}$ & 200 & 30 & & & & & & & N/A & 36.249 \\
\hline 3 & $\begin{array}{l}\text { FP-TTF- } \\
3\end{array}$ & 200 & $\begin{array}{r}32.6 \\
3\end{array}$ & 10 & & & & & & & N/A & 11.330 \\
\hline 4 & $\begin{array}{l}\text { FP-TTF- } \\
4\end{array}$ & 25 & 200 & 30 & & & & & & & N/A & 36.243 \\
\hline 5 & $\begin{array}{l}\text { FP-TTF- } \\
5\end{array}$ & 25 & 120 & 30 & & & & & & & N/A & 28.408 \\
\hline 6 & FP-EF-1 & 16 & 200 & & 15 & & & & & & N/A & 17.230 \\
\hline 7 & FP-EF-2 & 32.6 & 200 & & 15 & & & & & & N/A & 17.230 \\
\hline 8 & FP-EF-3 & 200 & $\begin{array}{r}32.6 \\
3\end{array}$ & & 5 & & & & & & N/A & 7.507 \\
\hline 9 & FP-EF-4 & 25 & 200 & & 15 & & & & & & N/A & 17.230 \\
\hline 10 & FP-EF-5 & 25 & 120 & & 15 & & & & & & N/A & 14.750 \\
\hline
\end{tabular}

\section{Conclusions and discussions on the results}

There were assessed ten types of flaws (thrugh thickness flaw and edge flaw) which were discovered in the wind turbine pillar - in the welded joint of the segment connection, 
Contemporary achievements in civil engineering 21. April 2017. Subotica, SERBIA

nearby the welded joint, in the flange of the segment joint. Different types of locations were taken into account thus resulting groups of flaws which were assessed and compared. The input data took into account the results from the FEM analysis of structure and the experimental results for material properties, all needed in the assessment procedures.

The comparison of the flaws assessment with fracture mechanics procedures, revealed several problems:

- Sensibility of the joints to the through thickness flaw in the endplate of the segment joint (FP-TTF-5). In case of a only 30mm flaw the element is considered unsafe.

- $\quad$ The edge flaw type - FP-EF-3 (flaw in the fillet welding of the shell element and the endplate - segment joint), is the most dangerous - a $15 \mathrm{~mm}$ crack depth into welded joint is a critical flaw for which the joint is considered unsafe.

\section{REFERENCES}

[1] Radu D., Feier A., Petzek E., Băncilă R., „Refurbishment of existing steel structures - an actual problem", Periodica Polytehnica Civil Engineering. Volum 2016 paper 9140 DOI 10.3311/Ppci.9140

[2] ***, EN 1090-2, "Technical requirements for the execution of steel structures", European Committee for Standardisation (CEN), Brussels

[3] M.F. Kanninen and C.H. Popelar, "Advanced Fracture Mechanics", Oxford University Press, 1985

[4] Milos Milosevic, Nenad Milosevic, Simon Sedmak, Uros Tatic "Digital image correlation in analysis of stiffness in local zones of welded joints", Tehnički vjesnik, Vol.23 No.1 Veljača 2016, DOI: 10.17559/TV-20140123151546

[5] ***, BS $7910 / \mathbf{2 0 1 3}$, "Guide to methods for assessing the acceptability of flaws in metallic structures", BSI British Standards 